(RESEARCH ARTICLE)

\title{
Improving the quality and the taste of green tea ice cream by identifying suitable cultivar, agronomic practices and processing techniques of Assamica tea grown in
} Sri Lanka

\author{
Dabaladeniya Sudilikara Gedara Gayathri Chathurika Swarnathilake and Don Chandana Abeysinghe * \\ Department of Plantation Management, Faculty of Agriculture and Plantation Management, Wayamba University of Sri \\ Lanka, Makandura, Gonawila (NWP),60170, Sri Lanka.
}

Publication history: Received on 30 September 2020; revised on 08 October 2020; accepted on 12 October 2020

Article DOI: https://doi.org/10.30574/wjarr.2020.8.1.0354

\begin{abstract}
The objectives of this study were to find the most suitable tea cultivar, shading effect and best tea processing technique for production of green tea powder with low astringency and amount of green tea addition to produce ice cream with best flavor and medicinal values. Green tea powder was manufactured using five different cultivars i.e. TRI 2023, TRI 2026, TRI 2027, TRI 4042 and TRI 4047 grown under shaded and un-shaded conditions with three processing techniques namely; steaming, pan firing and freeze drying and green tea ice cream was prepared using processed green tea powder. To reveal the health benefits of green tea powder and green tea ice cream, total phenolic content (TPC) , total flavonoid content (TFC) and Total antioxidant capacity (TAC) were checked by using modified folin-ciocalteu method, colorimetric method and ferric reducing antioxidant power (FRAP) assay respectively. The best quality green tea in terms of colour and flavour can be produced from tea leaves of TRI 4047 cultivar which was cultivated under shaded conditions with freeze drying processing technique. In terms of colour and flavour, $15 \mathrm{~g}$ of green tea added for ice cream mixture (500 mL of milk, $125 \mathrm{~mL}$ of whipping cream and $150 \mathrm{~g}$ of sugar) is the most suitable amount to add for green tea ice cream preparation. Significantly, higher TAC, TPC and TFC in green tea ice cream when compared to normal ice cream (without green tea powder) indicating the importance of consuming value added green tea ice cream as a healthy food.
\end{abstract}

Keywords: Consumer preference; Green tea ice cream; Processing technique; Shade effect; Tea cultivar

\section{Introduction}

Tea (Camellia sinensis L.) is the second mostly consumed beverage all around the world [1]. Sri Lanka is the $4^{\text {th }}$ biggest tea producing country in the world and produced 0.35 million tons in year 2018 with a production share of around $10 \%$ in the international sphere and one of the world leading exporter with a share of around 19\% of the global demand. Sri Lankan tea is well-known in the world for its' high quality and the taste [2]. Six different types of tea are produced from tea leaves. The main types are black tea, green tea and oolong tea. Green tea is prepared from unfermented leaves, oolong tea is produced by partial fermentation and black tea is produced by fully fermentation of tea leaves. Of the tea produced worldwide $78 \%$ is black tea which usually consumed in western countries, $20 \%$ green tea, normally consumed in Asian countries, and 2\% is Oolong tea which is mainly consumed in Southern China [3].

Nowadays, green tea is a popular beverage. Drinking habit of green tea was originated in China and has become in associated with many cultures in Asia from Japan to the Middle East. Recently, green tea has become more widespread in all over the world due to its health benefits [4]. Most of the health benefits are given due to the availability of

\footnotetext{
${ }^{*}$ Corresponding author: Don Chandana Abeysinghe

Department of Plantation Management, Faculty of Agriculture and Plantation Management, Wayamba University of Sri Lanka, Makandura, Gonawila (NWP),60170, Sri Lanka. 
polyphenols in green tea. Green tea contains the highest concentration of polyphenols compared to other types of tea. Polyphenols contained in tea are classified as catechins. An average cup of green tea (2.5 g of green tea leaves/200 ml of water) may contain $90 \mathrm{mg}$ of catechins. Green tea is said to contain over four times the concentration of antioxidant catechins than black tea [5]. Polyphenol is a powerful antioxidant that can neutralize free radicals of oxygen in the human body. Free radicals in the body make health problems as cancers and heart diseases [6]. Due to these beneficial constituents of green tea, it can be used as an ingredient for making value added tea based products.

Ice cream is one of the most popular foods item among consumers, not only children but also adults prefer to eat ice cream. Ice cream is prepared by churning and chilling a mixture containing milk, glucose based sweeteners and flavoring agents. Ice cream is a good source of energy. By adding green tea powder as a flavoring agent to ice cream, beneficial constituents of green tea may contribute to enhance the nutritional value of ice cream too. Therefore, green tea ice cream may be a good value added product of tea in terms of the flavor, nutritional and medicinal value.

However, in Sri Lanka, almost all the commercially-grown tea cultivars are originated from var. Assamica. Therefore, the quality of green tea produced in Sri Lanka is not much good due to possessing of higher content of phenolic compounds. The chemical composition of green tea varies with climate, season, cultivar, horticultural practices, age of the leaf (position of the leaf on the harvested shoot) and processing practices. Therefore, the suitable cultivars, shade levels and processing techniques have to be identified to produce green powder with low astringency.

This study was carried out to find the most suitable tea cultivar, shading effect and the best tea processing technique for production of green tea powder with low astringency and amount of green tea addition to produce ice cream with best flavor, nutritional and medicinal values.

\section{Material and methods}

\subsection{Location}

The experiment was carried out at the laboratory of Department of Plantation Management and Food Processing laboratory of Department of Food Science and Technology, Wayamba University of Sri Lanka from December 2015 to May in 2016.

\subsection{Experimental plot and Plant material}

Fresh tender shoots (Two leaves+Bud) of five different tea cultivars viz. TRI 2023, TRI 2026, TRI 2027, TRI 4042 and TRI 4047 which were grown in university tea garden were used to produce green tea. Whole tea field was separated into two plots including five cultivars in each plot. One plot was covered with a sixty per cent (60\%) shade net whereas the other plot was maintained without shade as a control plot. All management practices were carried out as the recommendation of the Tea Research Institute of Sri Lanka (TRISL).

\subsection{Methods}

\subsubsection{Processing of green tea powder by selected techniques}

Tea flushes from five different cultivars in both shaded and un-shade plots were used to produce green tea powder by using three processing techniques of steaming, pan firing and freeze drying.

In steaming method, harvested leaves were withered for $6 \mathrm{~h}$ and steamed for $1 \mathrm{~min}$ in a steamer to avoid fermentation and dried using a thermostat oven (Memmet, Germany) at $95^{\circ} \mathrm{C}$ for $21 \mathrm{~min}$. Dried leaves were ground into fine powder using a coffee blender.

Pan firing was done by firing $6 \mathrm{~h}$ withered leaves in a pan at $60-80{ }^{\circ} \mathrm{C}$ for $2 \mathrm{~min}$ to avoid fermentation. Other processing steps were similar to steaming. In freeze drying, harvested tea flushes were freeze dried for $24 \mathrm{~h}$ in a freeze dryer (Martin Christ Alpha 1-2 LD plus, Germany) and processed without $6 \mathrm{~h}$ withering process.

\subsubsection{Preparation of green tea ice cream}

$500 \mathrm{~mL}$ of fresh milk was mixed with $125 \mathrm{~mL}$ of whipping cream and mixed well. Sugar (150 g) and 3 egg yolks were added and stirred well using a beater for $10 \mathrm{~min}$. Ten gram of gelatin was boiled and added to the mixture. Four types of green tea ice cream were prepared by adding different quantities of green tea to the mixture as $5 \mathrm{~g}, 10 \mathrm{~g}$, $15 \mathrm{~g}$ and 20 
g. Ice cream was prepared by adding all ingredients except green tea powder as a control. Ice cream samples were kept in a refrigerator and mixture was beaten four times at 40 min intervals [7].

\subsubsection{Preparation of samples for chemical analysis}

Green tea powder

Green tea powder $(0.1 \mathrm{~g})$ was weighed into a $15 \mathrm{~mL}$ centrifuge tubes and added $5 \mathrm{~mL}$ of $80 \%$ methanol. Samples were homogenized for $1 \mathrm{~min}$ and vortexed for 40 seconds. Samples were placed in a water bath at $60^{\circ} \mathrm{C}$ for $40 \mathrm{~min}$ and vortex procedure was repeated in $10 \mathrm{~min}$ intervals. Then samples were centrifuged at 4,000 rpm for $5 \mathrm{~min}$ and supernatants were decanted into a $15 \mathrm{~mL}$ centrifuge tubes. Extraction procedure was repeated once again and both supernatants were pooled. The extracts were stored at $-20^{\circ} \mathrm{C}$ until analysis.

\section{Tea ice-cream extracts}

Ten gram of ice cream was mixed with $50 \mathrm{~mL}$ of absolute ethanol and left to stand at room temperature (approximately $28{ }^{\circ} \mathrm{C}$ ) for $24 \mathrm{~h}$ and then centrifuged at $4,000 \mathrm{rpm}$ for $10 \mathrm{~min}$. The clear supernatant was separated and stored at $-20^{\circ} \mathrm{C}$ prior to analysis [8].

\subsubsection{Determination of bioactive compounds and antioxidant capacity}

The total phenolic content (TPC) was quantified using a modified folin-ciocalteu method [9] and TPC in one gram of green tea powder or ice cream was calculated and expressed as milligram of gallic acid equivalent (GAE).Total flavonoid content (TFC) was determined by a colorimetric method as described by Liu et al., [10] with slight modifications and TFC in one gram of sample was calculated and expressed as mg of rutine equivalent (RE). Total antioxidant capacity (TAC) was determined using ferric reducing antioxidant power (FRAP) assay as described by Benzie and Stain [11] and TAC in one gram of sample was calculated and expressed as mg of trolox equivalent (TE).

\subsubsection{Determination of chlorophyll content}

Chlorophyll content of tea flushes from each cultivar in non-shaded and shaded plots were determined.

\subsubsection{Sensory Evaluation}

Tasters for tea tasting were initially identified by conducting a triangular test [12]. Tea tasting was conducted to determine the shading effect through the bitterness of green tea liquor. Two grams of green tea from each cultivar from the shaded and the control was weighed into 10 tea cups separately and $100 \mathrm{~mL}$ of 'simmering water' (avoided boiling water) was added to each cup, covered and allowed to infuse for $3 \mathrm{~min}$. The infusions were stirred and removed from the tea cups to avoid excessive diffusion of tannins. Then the random numbers were given to each cultivar and 10 tea cups were labeled with random numbers. Untrained panelists (30) were used for testing bitterness of prepared green tea liquor. After serving prepared green tea liquor, consumers were asked to rate the bitterness of the liquor following Likert Scale and then the section of the tea field that results the least bitterness in green tea was identified. The section of the field that results least bitterness in green tea was used for further analysis. Same tea tasting panels were used to identify the best cultivar and processing technique.

Likert Scale had five ratings viz. 1- Very low bitter, 2- Low bitter, 3- Moderately bitter, 4- High bitter, 5-Very high bitter

Consumer preference of green tea ice cream was determined by Hedonic Test [13]. Colour, taste and texture were used as quality parameters of green tea ice cream and 30 untrained panelists were used for this test. After serving prepared green tea ice cream, consumers were asked to rate the given quality parameters according to following Scale; 1- Like extremely, 2- Like moderately, 3- Like, 4- No comment, 5- Dislike, 6- Dislike moderately, 7- Dislike extremely.

\subsubsection{Statistical analysis}

Statistical comparisons of mean values for parametric data was performed by general liner model (GLM) of ANOVA followed by Turkey multiple ranges test using SAS (SAS Institute, 1999) and presented as mean \pm SD with $95 \%$ confident level. Mean comparisons of consumer preferences (non-parametric data) were analyzed with Ordinal Logistic Regression using SPSS (version 16) statistical software. 


\section{Results and discussion}

In the study, attempts were made to investigate the variations of content of the most important secondary metabolites (phenolics and flavonoids) and bioactivity such as total antioxidant capacity of green tea powder manufactured from tender flushes (Two leaves+Bud) of Camellia sinensis var. Assamica under shaded and un-shaded conditions. Green tea powder produced under un-shaded condition had significantly $(\mathrm{p}<0.05)$ higher total antioxidant capacity (TAC), total phenolic content (TPC) and total flavonoid content (TFC) when compared to that produced under shaded condition (Table1).

Table 1 Total Antioxidant Capacity (TAC), Total Phenolic Content (TPC) and Total Flavonoid Content (TFC) of green tea powder manufactured from tea flushes under shaded and un-shaded conditions.

\begin{tabular}{|l|l|l|l|}
\hline Treatment & $\begin{array}{l}\text { TAC } \\
\text { (mg TE/g DW) }\end{array}$ & $\begin{array}{l}\text { TPC } \\
\text { (mg GAE/g DW) }\end{array}$ & $\begin{array}{l}\text { TFC } \\
\text { (mg RE/g DW) }\end{array}$ \\
\hline Shaded & & & \\
\hline TRI 2023 & $445.7 \pm 1.9^{\mathrm{d}}$ & $256.4 \pm 1.1^{\mathrm{ab}}$ & $111.4 \pm 5.2^{\mathrm{bc}}$ \\
\hline TRI 2026 & $415.6 \pm 2.4^{\mathrm{g}}$ & $220.1 \pm 1.6^{\mathrm{d}}$ & $107.1 \pm 5.2^{\mathrm{c}}$ \\
\hline TRI 2027 & $424.3 \pm 1.7^{\mathrm{f}}$ & $183.8 \pm 1.4^{\mathrm{f}}$ & $117.62 \pm 4.4^{\mathrm{abc}}$ \\
\hline TRI 4042 & $433.7 \pm 2.9^{\mathrm{e}}$ & $237.8 \pm 1.2^{\mathrm{c}}$ & $114.8 \pm 4.4^{\mathrm{abc}}$ \\
\hline TRI 4047 & $382.5 \pm 3.8^{\mathrm{h}}$ & $161.8 \pm 2.3^{\mathrm{g}}$ & $94.8 \pm 3.3^{\mathrm{d}}$ \\
\hline Un-Shaded & & & \\
\hline TRI 2023 & $500.5 \pm 2.3^{\mathrm{a}}$ & $261.8 \pm 4.7^{\mathrm{a}}$ & $122.4 \pm 4.4^{\mathrm{ab}}$ \\
\hline TRI 2026 & $451.9 \pm 0.9^{\mathrm{b}}$ & $254.1 \pm 1.2^{\mathrm{b}}$ & $119.5 \pm 4.4^{\mathrm{ab}}$ \\
\hline TRI 2027 & $479.5 \pm 2.9^{\mathrm{c}}$ & $242.4 \pm 1.1^{\mathrm{c}}$ & $125.2 \pm 3.6^{\mathrm{a}}$ \\
\hline TRI 4042 & $489.1 \pm 2.5^{\mathrm{a}}$ & $260.6 \pm 1.4^{\mathrm{a}}$ & $123.8 \pm 2.9^{\mathrm{a}}$ \\
\hline TRI 4047 & $423.5 \pm 2.2^{\mathrm{f}}$ & $206.3 \pm 0.6^{\mathrm{e}}$ & $110.5 \pm 4.4^{\mathrm{bc}}$ \\
\hline
\end{tabular}

Means in a column followed by the same letters are not significantly different at 0.05 level; TE- Trolox Equivalent; GAE- Gallic Acid Equivalent; RERutine Equivalent; DW- Dry Weight

Theanine is one of the major amino acids found in green tea and responsible for the refined flavor and sweetness, and is a major flavor compound in green tea. Catechins are a type of polyphenol and are the main astringent compound in green tea and have antioxidant properties. The conversion of theanine to catechins, is catalyzed by sunlight. Cultivation in the shade can restrict this chemical reaction resulting in leaves rich in theanine and caused for lower production of catechins [14]. Therefore, lower levels of catechine compounds in shaded green tea may lead to produce lesser TAC, TPC and TFC when compared to un-shaded green tea and ultimately affect for low level of astringent compounds, resulting the less bitterness in sensory evaluation (Table 2).

Table 2 Shading effect on bitterness of green tea powder

\begin{tabular}{|l|l|l|}
\hline Shade condition & Number of observations & Mean value \\
\hline Shaded & 150 & $2.6 \pm 0.8$ \\
\hline Un-shaded & 150 & $3.2 \pm 0.9$ \\
\hline
\end{tabular}

Low mean values in the mean value column refers to low bitterness.

Total chlorophyll content in tea leaves of the five selected cultivars under shaded condition was significantly (p<0.05) higher than total chlorophyll content in un-shaded tea leaves (Figure 1). Higher amounts of chlorophyll may contribute to maximize photosynthesis reaction under limited light condition and makes tea less astringent and with better colour and appearance [15]. 


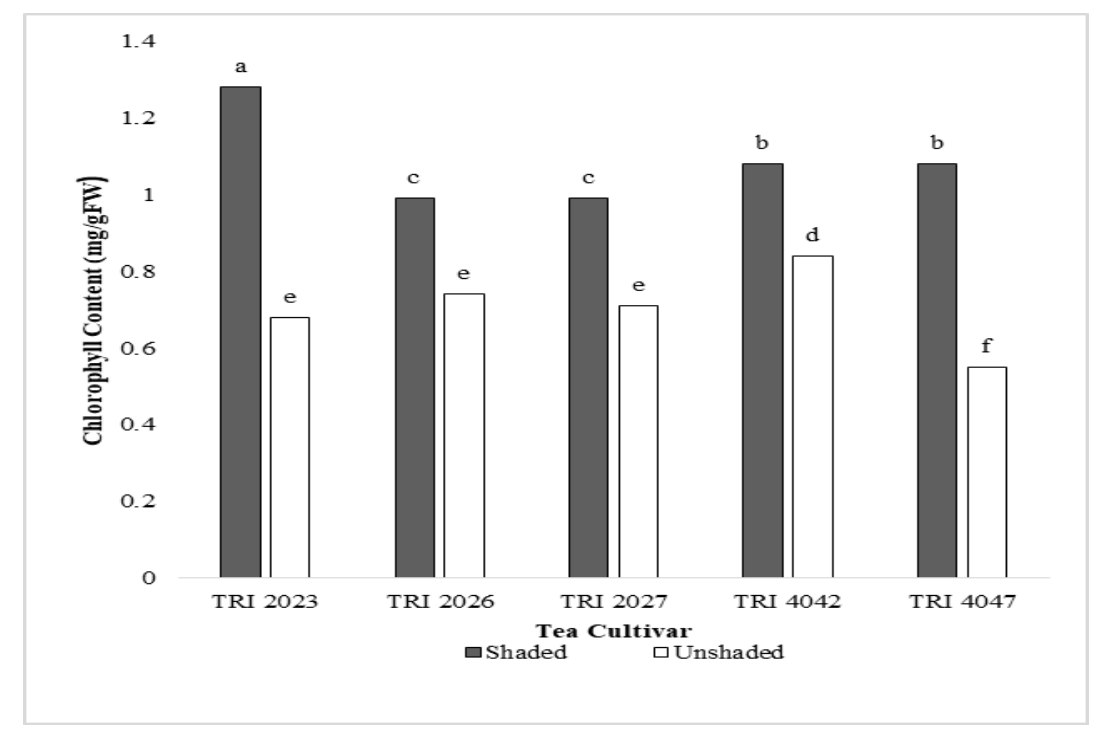

Figure 1 Total chlorophyll content of tea leaves under shaded and un-shaded conditions Means followed by same letters are not significantly different at $\mathrm{p}<0.05$; FW; Fresh Weight

Bitterness of green tea extract processed from shaded tea flushes was tested against three processing techniques, i.e. steaming, pan firing and freeze drying through consumer preference. Freeze drying technique resulted the least bitterness in green tea compared to steaming and pan firing (Table 3). The least bitterness through freeze drying technique may be due to minimum leaf damage during processing.

Table 3 Identification of the best processing technique based on bitterness

\begin{tabular}{|l|l|l|}
\hline Processing technique & Number of observations & Mean value \\
\hline Steaming & 150 & $3.0 \pm 1.5$ \\
\hline Pan firing & 150 & $4.1 \pm 0.8$ \\
\hline Freeze drying & 150 & $1.9 \pm 0.8$ \\
\hline \multicolumn{2}{|c|}{ Low means in the mean value column refers to low bitterness. }
\end{tabular}

Bitterness of green tea extract which was processed from tea flushes under shaded condition with freeze drying technique was tested against five cultivars through consumer preference. A significant $(\mathrm{p}<0.05)$ least bitterness of green tea liquor was observed in TRI 4047 cultivar when compared to other four selected cultivars (Table 4). Shaded TRI 4047 has low amount of TAC (423.5 mg TE/g DW), TPC (206.3 mg GAE/g DW) and TFC (110.5 mg RE/g DW) with compared to other shaded tea cultivars (Table 1). Therefore, lower level of astringent compound may lead to reduce bitterness and enhance the flavor.

Table 4 Identification of the best tea cultivar based on bitterness

\begin{tabular}{|l|l|l|}
\hline Tea cultivar & Number of observations & Mean value \\
\hline TRI 2023 & 30 & $4.6 \pm 0.6$ \\
\hline TRI 2026 & 30 & $3.8 \pm 1.1$ \\
\hline TRI 2027 & 30 & $2.4 \pm 0.9$ \\
\hline
\end{tabular}




\begin{tabular}{|l|l|l|}
\hline TRI 4042 & 30 & $3.0 \pm 0.9$ \\
\hline TRI 4047 & 30 & $1.2 \pm 0.1$ \\
\hline \multicolumn{2}{|c|}{ Low mean values in the mean value column refers to low bitterness. }
\end{tabular}

Consumer preference for green tea ice creams which were prepared by varying amounts ( $5 \mathrm{~g}, 10 \mathrm{~g}, 15 \mathrm{~g}$ and $20 \mathrm{~g}$ ) of powdered green tea (TRI 4047) was tested using a tasting panel by sensory evaluation. The results revealed that $15 \mathrm{~g}$ of green tea powder in ice cream formula gives the best colour, taste and texture with compared to other green tea concentrations (Table 5).

Table 5 Consumer preference for green tea ice cream with varying concentration of green tea

\begin{tabular}{|l|l|l|l|}
\hline $\begin{array}{l}\text { Green tea } \\
\text { powder } \mathbf{( g )}\end{array}$ & $\begin{array}{l}\text { Mean value } \\
\text { for colour }\end{array}$ & $\begin{array}{l}\text { Mean value } \\
\text { for taste }\end{array}$ & $\begin{array}{l}\text { Mean value } \\
\text { for texture }\end{array}$ \\
\hline 5 & $3.23 \pm 0.6$ & $3.17 \pm 0.2$ & $3.1 \pm 0.1$ \\
\hline 10 & $2.27 \pm 0.8$ & $2.23 \pm 0.3$ & $2.37 \pm 0.5$ \\
\hline 15 & $1.17 \pm 0.3$ & $1.23 \pm 0.7$ & $1.3 \pm 0.2$ \\
\hline 20 & $3.27 \pm 0.4$ & $4.17 \pm 0.5$ & $3.7 \pm 0.6$ \\
\hline
\end{tabular}

There were significant $(\mathrm{p}<0.05)$ variations in total antioxidant capacity (TAC), total phenolic content (TPC) and total flavonoid content (TFC) in green tea ice cream prepared with varying concentration of green tea powder (Table 6). Green tea ice cream had significantly higher TAC, TPC and TFC when compared to ice cream without green tea powder (control).

Table 6 Total Antioxidant Capacity (TAC), Total Phenolic Content (TPC) and Total Flavonoid Content (TFC) of green tea ice cream at different concentration of green tea powder.

\begin{tabular}{|l|l|l|l|}
\hline $\begin{array}{l}\text { Green tea } \\
\text { powder (g) }\end{array}$ & $\begin{array}{l}\text { TAC } \\
\text { (mg TE/100g FW) }\end{array}$ & $\begin{array}{l}\text { TPC } \\
\text { (mg GAE/100g FW) }\end{array}$ & $\begin{array}{l}\text { TFC } \\
\text { (mg RE/100g FW) }\end{array}$ \\
\hline 0 & $6.1 \pm 0.1^{\mathrm{e}}$ & $2.6 \pm 0.2^{\mathrm{e}}$ & $0.00 \pm 0.0^{\mathrm{e}}$ \\
\hline 5 & $443.3 \pm 13.9^{\mathrm{d}}$ & $105.3 \pm 12.0^{\mathrm{d}}$ & $1.2 \pm 0.02^{\mathrm{d}}$ \\
\hline 10 & $539.2 \pm 14.3^{\mathrm{c}}$ & $254.3 \pm 12.5^{\mathrm{c}}$ & $2.3 \pm 0.03^{\mathrm{c}}$ \\
\hline 15 & $757.9 \pm 11.0^{\mathrm{b}}$ & $324.3 \pm 13.8^{\mathrm{b}}$ & $3.1 \pm 0.02^{\mathrm{b}}$ \\
\hline 20 & $1018.1 \pm 11.2^{\mathrm{a}}$ & $447.3 \pm 9.0^{\mathrm{a}}$ & $3.4 \pm 0.02^{\mathrm{a}}$ \\
\hline
\end{tabular}

Means in a column followed by the same letters are not significant at $\mathrm{p}<0.05$; TE- Trolox Equivalent; GAE- Gallic Acid Equivalent; RE- Rutine Equivalent; FW- Fresh weight; 0-Control

\section{Conclusion}

The best quality green tea in terms of colour and flavour can be produced from tea leaves of TRI 4047 cultivar which was cultivated under shaded conditions with freeze drying processing technique. In terms of colour and flavour, $15 \mathrm{~g}$ of green tea added for ice cream mixture ( $500 \mathrm{~mL}$ of milk, $125 \mathrm{~mL}$ of whipping cream and $150 \mathrm{~g}$ sugar) is the most suitable amount to add for green tea ice cream preparation. Significantly, higher TAC, TPC and TFC in green tea ice cream when compared to normal ice cream (without green tea powder) indicating the importance of consuming value added green tea ice cream as a healthy food. 


\section{Compliance with ethical standards}

\section{Acknowledgments}

Authors wish to express their gratitude to Mr. W.A.R. Wijesooriya, Technical Officer, Mr. H.M.A.S. Bandara and Mr. W.M.U.S. Bandara, Lab Attendants and Mr. S.P.A. Karunarathna, Field Supervisor Department of Plantation Management, Wayamba University of Sri Lanka for their help. Further, we acknowledge Non-academic staff members, Department of Food Science and Technology, Faculty of Livestock Fisheries and Nutrition for supporting in laboratory work.

\section{Disclosure of conflict of interest}

The authors whose names are listed immediately below certify that they have NO affiliations with or involvement in any organization or entity with any financial interest or non-financial interest in the subject matter or materials discussed in this manuscript.

\section{References}

[1] Hameed A, Naveed S, Wishah Z. Consumption of Green Tea in Professionals and Non-Professionals. American Journal of Drug Delivery and Therapeutics. 2014; 1: 82-88.

[2] Anonyme,Industry capability report. Export agriculture division, Sri Lanka export development board, Sri Lanka. 2019; $1-10$.

[3] Nishant R, Jigisha A, Kumar Navin, Pankaj G. Green tea: A magical herb with miraculous outcomes. International Research Journal of Pharmacy. 2012; 3:139-148.

[4] Benzie IF, Szeto YT, Strain JJ, Tomlinson B. Consumption of green tea causes rapid increase in plasma antioxidant power in humans. Nutrition and cancer. 1999; 34: 83-87.

[5] Wu CD, Wei GX. Tea as a functional food for oral health. Nutrition. 2002; 18: 443-444.

[6] Thasleema SA. Green tea as an antioxidant. Journal of Pharmaceutical Sciences and Research. 2013; 5(9): 171173.

[7] Jennifer BJ. Matcha green tea ice cream. 2016.

[8] Limsuwan T, Paekul N, Thongtan J, Tangkanakul P. Total phenolic compounds, antioxidant activity and nutritional values of sugar-free and reduced-fat milk-based ice cream enriched with selected herb ingredients. khon kaen university research journal. 1994; 19(4): 515-526.

[9] Abeysinghe DC, Li X, Sun C, Zhang W, Zhou C, Chen K. Bioactive compounds and antioxidant capacities in different edible tissues of citrus fruit of four species. Food chemistry. 2007; 104: 1338-1344.

[10] Liu M, Li XQ, Weber C, Lee CY, Brown J, Liu RH. Antioxidant and anti-proliferative activities of raspberries. Journal of Agriculturtal and Food Chemistry. 2002; 50: 2926-2930.

[11] Benzie IFF, Strain JJ. The ferric reducing ability of plasma as a measure of antioxidant power: The FRAP assay. Journal of analytical Biochemistry. 1996; 293: 70-76.

[12] Rogers EK, Brimelow CJB. Instrumentation and sensors for the food industry. 2 nd ed. 2001; 36-37.

[13] Potter NN, Hotchkiss JH. Food Science. $5^{\text {th }}$ ed. New York, Chapman and Hall. 1996.

[14] Nakamura Y. Scientific Evidence for the Health Benefits of Green Tea. Characteristics of Japanese Green Tea. 2015; $1: 14-22$.

[15] Mahanta PK, Baruah S. Changes in pigments and phenolics and their relationship with black tea quality. Journal of agricultural and food chemistry. 2006; 59: 21-26. 